\title{
Mistaken Identity for Gastric Carcinoma
}

\begin{abstract}
Isolated gastric tuberculosis, without evidence of pulmonary or other gastrointestinal involvement, is extremely rare. Due to inaccurate clinical diagnoses, most patients end up requiring surgical intervention,only after which is gastric tuberculosis diagnosed. we present a case where this dilemma between tuberculosis and malignancy costed the patient half of his stomach.
\end{abstract}

Keywords: Gastric carcinoma, granulomas, tuberculosis

\section{Introduction}

Isolated gastric tuberculosis (TB), without evidence of pulmonary or other gastrointestinal (GI) involvement, is extremely rare, even in parts of the world where intestinal TB is common. The incidence of gastric TB, whether as a primary or secondary infection, is found in only $0.03 \%-0.21 \%$ of all routine autopsies, and in $0.3 \%-2.3 \%$ of autopsies of patients with known concurrent pulmonary TB..$^{[1,2]}$

\section{Case Summary}

A 40-year-old female, hypothyroid, presented with dyspepsia, weight loss, fever for 2 months. She had a history of pulmonary TB 6 years back and treated by directly observed treatment short-course Revised National TB Control Program regieme. Clinical examination was unremarkable. All baseline investigations including complete blood count, blood chemistry, chest X-ray, ultrasound abdomen were normal. A 4 weeks Proton-pump inhibitor therapy could not relieve her symptoms. Upper GI tract (GIT) screening was done which showed an irregular ulcer measuring $1 \mathrm{~cm}$ at incisura and another circumscribed ulcer about $5 \mathrm{~mm}$ at the junction of body and antrum. Histopathology revealed mononuclear infiltrate with doubtful granuloma formation. Repeat endoscopy after a month revealed an infiltrative growth involving lower two-thirds of the stomach [Figure 1]. An impression of carcinoma stomach was

This is an open access journal, and articles are distributed under the terms of the Creative Commons Attribution-NonCommercial-ShareAlike 4.0 License, which allows others to remix, tweak, and build upon the work non-commercially, as long as appropriate credit is given and the new creations are licensed under the identical terms.

For reprints contact: reprints@medknow.com made by the endoscopist, but histopathology revealed chronic inflammatory granulation tissue with many acute Inflammatory cells with occasional cluster of epitheloid cells in lamina propria. Contrast-enhanced computed tomography abdomen showed a Circumferential mural thickening at the antropyloric region of the stomach with the ill-defined fat plane, with multiple peripyloric lymph nodes [Figure 2]. Patient was referred to a surgical oncologist who operated her. Distal subtotal gastrectomy with Billroth II reconstruction was done.

\section{Intra operative findings}

- Diffuse growth at incisura angularis with the involvement of serosa

- Ascitis

- Enlarged infrapyloric, pre-pyloric group of lymph nodes.

The specimen on histopathology revealed granulomas formation and was referred by oncology section to Infectious diseases department for review.

The patient was evaluated for concomitant TB. Chest X-ray was normal, sputum and urine for acid-fast bacteria were negative. High erythrocyte sedimentation rate of $60 \mathrm{~mm} / \mathrm{h}$ with mild anemia of chronic disease was found. Mantoux was positive $(20 \mathrm{~mm})$.

Review histopathology of the specimen showed chronic inflammatory infiltrate comprising mostly lymphocytes forming follicles at places. Lymphnodes showed epithelioid granulomas with Langhans type giant cells. The patient was put on anti-tubercular therapy. A basket of four drugs for 2 months and two drugs for next

\footnotetext{
How to cite this article: Koul AN, Rather AR. Mistaken identity for gastric carcinoma. Indian J Med Paediatr Oncol 2019;40:591-3.
}

\author{
Ajaz Nabi Koul, \\ Aadil Rafeeq Rather \\ Department of Medicine and \\ Infectious Diseases, SKIMS, \\ Srinagar, Jammu and Kashmir, \\ India
}

Submission: 05-May-2018 Accepted in Revised Form: 21-Jun-2018

Published: 17-Feb-2020

Address for correspondence: Dr. Ajaz Nabi Koul, Department of Medicine and Infectious Diseases, SKIMS, Srinagar, Jammu and Kashmir, India.

E-mail:ajazkoul@yahoo.com

Access this article online

Website: www.ijmpo.org

DOI: 10.4103/ijmpo.jimpo_105_18 Quick Response Code:

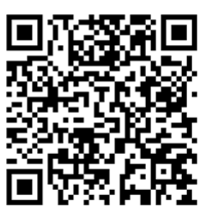




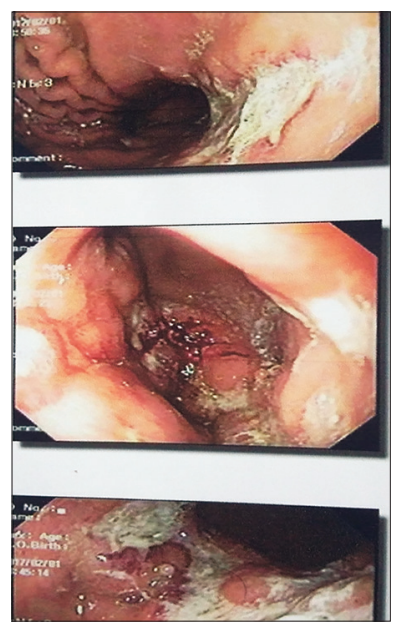

Figure 1: Endoscopy showing a slough, altered blood, ulcer

4 months was given. Ascitis resolved completely with resolution of pre-pyloric lymph nodes. The weight and general well-being of the patient were improved at 6 month follow-up with check ultrasound revealing a normal picture and check endoscopy showing a normal stomach with evidence of distal gastrectomy.

\section{Discussion}

TB can involve any part of GIT from mouth to anus, the peritoneum, and the pancreatobiliary system. Gastric TB is a rare condition. The relative rarity of gastric $\mathrm{TB}$ can be attributed to the:

- Bactericidal properties of gastric acid

- The scarcity of lymphoid tissue in the gastric wall

- The continuous motor activity of the stomach. ${ }^{[1]}$

Almost always located in the antrum or prepyloric region. Gastric TB normally occurs secondarily to pulmonary TB or another organic infection. It has been postulated that the causes of isolated primary gastric TB may include the ingestion of unpasteurized milk infected with bovine TB or a severely immunocompromised condition. ${ }^{[2]}$ Secondary TB occurs when patients with active pulmonary TB swallow tuberculous bacilli. Other possible mechanisms include direct mucosal invasion, hematogenous spread, extension from adjacent structures, and superinfection of a pre-existing ulcer or malignancy. ${ }^{[2,3]}$ In cases of gastric TB, nodal involvement is usually extensive. Route of spread is thought to be the celiac lymph nodes. Abdominal pain is the symptom most commonly associated with GI TB. Other symptoms, including diarrhea, fever, anorexia, weight loss, and constipation, are usually observed, but hematemesis is extremely rare. ${ }^{[1,4,5]}$ It has also been suggested that, although intestinal TB results in increased capillary vascularity, small arteries undergo obliterative endarteritis in TB. This would explain the rarity of bleeding in such cases. ${ }^{[6]}$ Endoscopy plays an important role in diagnosis. Single and multiple ulcers have been associated with this disease, as have hypertrophic nodular lesions surrounding a stenotic pyloric

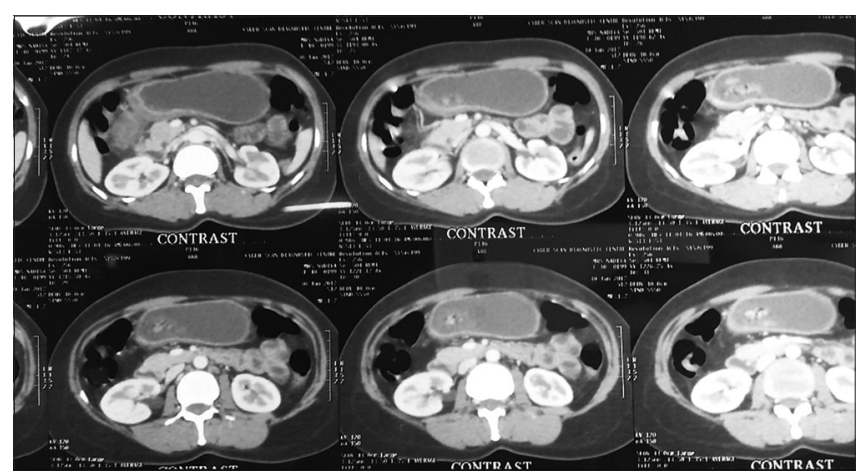

Figure 2: Contrast-enhanced computed tomography abdomen showing the thickened antropyloric junction

channel. ${ }^{[1]}$ The associated ulcers are typically found to be irregular with a necrotic base, which may extend into the perforation. A definitive diagnosis essentially relies on a histological approach, normally involving the Ziehl-Neelsen staining for acid-fast bacilli and culturing. Histopathological findings of caseating epithelioid cell granulomas are very helpful. However, diagnosis cannot always be made from the specimens taken by endoscopy. Granulomas, whether caseous or noncaseous, are frequently found to be negative on endoscopic biopsies. ${ }^{[7]}$ This may be the reason for the paucity of diagnosis on endoscopic biopsy of our patient. One of the reasons for this is the very low diagnostic yield of endoscopic biopsy specimens. In such cases, tumors that do not originate from the mucosa, such as GI stromal tumor and lymphoma should generally be considered. Polymerase chain reaction testing of biopsy specimens may facilitate diagnosis and allow the exclusion of Crohn's disease with a $100 \%$ specificity and a sensitivity of $27 \%-75 \%$. Radiological investigations including computed tomography are sensitive in detecting the local burden of pathology, i.e., the extent of involvement, surrounding infiltration as well as complications like perforation. However, most of the radiological features in these cases are indistinguishable from primary malignant lesions of upper GI and therefore warrant confirmation by histopathology.

\section{Conclusion}

Although gastric TB is a rare condition, in patients presenting with endoscopic evidence of diffuse chronic inflammatory activity, the possibility of gastric TB should be considered, particularly in areas in which TB maintains endemicity. ${ }^{[3]} \mathrm{TB}$ is a great mimicker. It is also a disease that can be easily controlled and treated. Clinicians need to be aware of the myriad manifestations of TB and resist the temptation of premature diagnostic closure. Due to inaccurate clinical diagnoses, most patients end up requiring surgical intervention, only after which is gastric TB diagnosed.

\section{Declaration of patient consent}

The authors certify that they have obtained all appropriate patient consent forms. In the form the patient(s) has/have 
given his/her/their consent for his/her/their images and other clinical information to be reported in the journal. The patients understand that their names and initials will not be published and due efforts will be made to conceal their identity, but anonymity cannot be guaranteed.

\section{Financial support and sponsorship}

Nil.

\section{Conflicts of interest}

There are no conflicts of interest.

\section{References}

1. Bandyopadhyay SK, Bandyopadhyay R, Chatterjee U. Isolated gastric tuberculosis presenting as haematemesis. J Postgrad Med
2002;48:72-3.

2. Lin OS, Wu SS, Yeh KT, Soon MS. Isolated gastric tuberculosis of the cardia. J Gastroenterol Hepatol 1999;14:258-61.

3. Amarapurkar DN, Patel ND, Amarapurkar AD. Primary gastric tuberculosis - Report of 5 cases. BMC Gastroenterol 2003;3:6.

4. Settbas Y, Alper M, Akcan Y, Gurbuz Y, Oksuz S. Massive gastrointestinal tuberculosis in a young patient without immunosuppression. World J Gastroenterol 2003;9:2382-4.

5. Rathnaraj S, Singh SK, Verghese M. Gastric tuberculosis presenting with hematemesis. Indian J Gastroenterol 1997;16:110-1.

6. Watanabe T, Kudo M, Kayaba M, Shirane H, Tomita S, Orino A, et al. Massive rectal bleeding due to ileal tuberculosis. J Gastroenterol 1999;34:525-9.

7. Kim SE, Shim KN, Yoon SJ, Jung SA, Kim TH, Yoo K, et al. A case of gastric tuberculosis mimicking advanced gastric cancer. Korean J Intern Med 2006;21:62-7. 